Ecology/Écologie

\title{
Comparative flight morphology in queens of invasive and native Patagonian bumblebees (Hymenoptera: Bombus)
}

\author{
Carlo Polidori *, José Luis Nieves-Aldrey
}

Departamento de Biodiversidad y Biología Evolutiva, Museo Nacional de Ciencias Naturales (CSIC), C/José Gutiérrez Abascal 2, 28006 Madrid, Spain

\section{A R T I C L E I N F O}

\section{Article history:}

Received 17 July 2014

Accepted after revision 3 November 2014

Available online 9 December 2014

\section{Keywords:}

Bombus dahlbomii

Bombus terrestris

Flight muscle ratio

Wing loading

Wing aspect ratio

\begin{abstract}
A B S T R A C T
Since its introduction in Chile, the European Bombus terrestris L. (Hymenoptera: Apidae) has progressively reduced the abundance of the native Patagonian bumblebee, Bombus dahlbomii Guérin. Because an important cause of successful invasion of a species may depend on a potentially advantageous phenotype, we studied morphologies related to flight performance (flight muscle ratio (FMR), wing loading (WL), excess power index (EPI, which integrates FMR and $\mathrm{WL}$ ) and wing aspect ratio (AR)) in the queens of the two species. Previous empirical studies showed that greater FMR, AR and EPI, and lower WL increase flight performance. In the Patagonian Chilean fjord where the study was carried out, $B$. dahlbomii was $40 \%$ heavier than $B$. terrestris, a difference theoretically allowing the queens of the native species to take off with heavier loads, despite the fact that the two species have virtually identical FMRs. However, FMR negatively depended on body mass at the intra-specific level. The total wing area was $35 \%$ greater in $B$. dahlbomii, but the difference in forewing length was only of $16 \%$. Once taken into account the effect of body size, WL, was significantly lower in $B$. terrestris. AR increased with body mass and did not differ between species. EPI was weakly but significantly higher in $B$. terrestris. Experiments formally linking such parameters with flight performance may help to explain the observed quick and wide spread of this alien species in Patagonia in the last few years.

(c) 2014 Académie des sciences. Published by Elsevier Masson SAS. All rights reserved.
\end{abstract}

\section{Introduction}

Bombus dahlbomii Guérin (Hymenoptera: Apidae) (Fig. 1A) is one of the largest bumblebees of world and an emblematic species endemic to the temperate forests of southern South America. The species is distributed from central to southern Chile and Argentina [1], and is the only native bumblebee in southern South America [2]. In Patagonia, however, $B$. dahlbomii has co-existed for 30 years, with at least two alien congeneric species, Bombus terrestris L. (Fig. 1B) and Bombus ruderatus (Fabricius) [2]. These two species have been introduced

\footnotetext{
* Corresponding author.

E-mail address: cpolidori@mncn.csic.es (C. Polidori).
}

for commercial purposes to increase the yield of seeds in cultivated crops, as well as to improve the production of fruits in tree orchards [3]. However, the invasive potential of such bee species was underestimated at the time of release, and increasing evidence indicates that they are having impressively rapid negative impacts on B. dahlbomii populations, with the southward spread of the alien species being concurrent with the geographic retraction of $B$. dahlbomii $[4,5]$.

To predict and possibly prevent future invasions, it is important to understand which traits make a species a successful, thus, potentially invasive, species. Apart from the number of individuals initially released [6,7], a potentially invasive species should possess certain lifehistory traits that allow problems associated with smallpopulation size at the introduction time to be overcome 

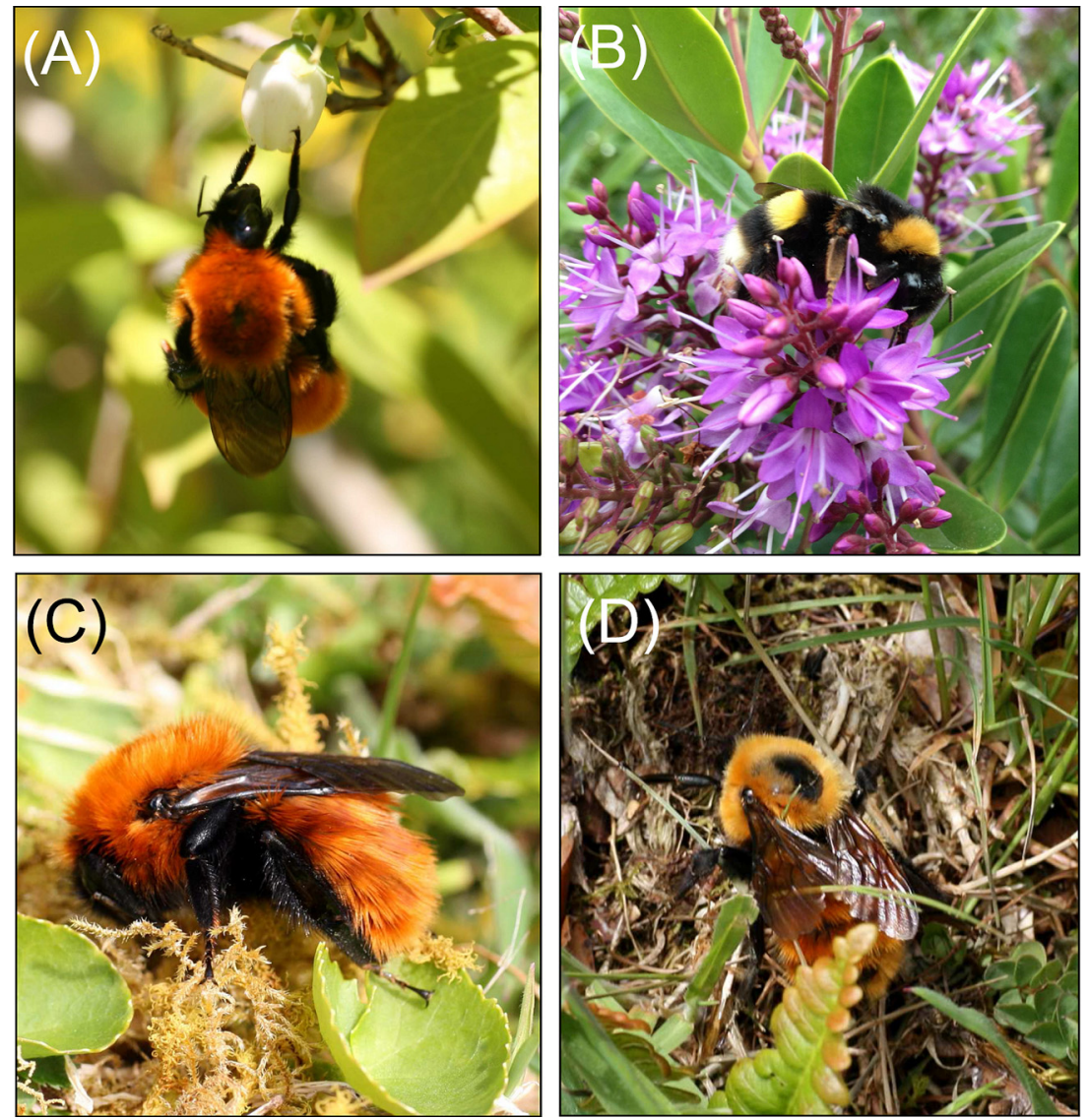

Fig. 1. (Colour online) Queens of the bumblebees Bombus dahlbomii (A) and Bombus terrestris (B) at Huinay Scientific Field Station, Southern Chile. (C) and (D) show queens of $B$. dahlbomii while patrolling grassy ground patches (C) and digging through vegetation within grassy patches (D), probably in search of a nest site to occupy.

and which allow competition with closely related native species. These traits include wider habitat or dietary niches [8] and behavioural flexibility [9]. Some morphological traits also could be important in favouring invasion, but they were less investigated, with body size possibly the only factor considered to date (with invasion generally associated with decreasing size) [10-13].

At present, the mechanisms underlying the decline of B. dahlbomii in Patagonia are only partially understood. Recent research suggested the potential roles of exploitative competition [14] and of pathogen co-introduction $[5,15]$. Here, we compared the morphology related to the flight apparatus between queens of both species. Individual queens of Bombus spp. found their colonies in spring by colonizing and modifying subterranean cavities (e.g., burrows of rodents) [16]. They then provision their first worker brood immatures with pollen and nectar. The foraging activity of queens stops when the first adult workers emerge and start foraging to feed their immature sisters [16]. The period of colony foundation and firstbrood foraging is thus critical for queens.

Based on previous empirical studies, it is possible to make predictions about the relationship between morphology and flight performance. In particular, for insects (including bumblebees), such studies revealed that flight muscle ratio (i.e. the flight muscle mass to body mass ratio, FMR) is the most important determinant for take off ability with additional loads (together with body mass), as well as for manoeuvrability and acceleration capacity in flight [17]. Variation in the relative size of flight muscles also affects the thermal breadth for flight (i.e. the range of ambient and muscle temperature over which flight is possible): insects with higher FMRs should be capable of maintaining flight at lower thoracic temperatures [18]. Furthermore, relatively larger wings compared to body size, corresponding to a lower wing loading (WL)(i.e. the body mass to wing area ratio) are also associated with a superior flying ability [19,20], since it allows a more energetically efficient flight and take off at higher speed [21,22] (though acceleration capacity seems to increase with WL [23]). Improved ability to fly at low temperatures was also associated with an increase in wing area (lower WL) [24].

FMR and WL can be integrated to obtain the Excess Power Index (EPI), which represents the maximum power available to the bee over the power required to maintain equilibrium in steady-level flight [25]. This index was previously used as a general estimate of flight ability [2628]. An additional morphological trait, the wing aspect ratio (AR), which describes the wing shape (how elongated 
wings are), was also correlated positively with flight manoeuvrability, acceleration and lift increase per weight unit $[29,30]$.

\section{Methods}

\subsection{Study area and sample collection}

All the individuals of $B$. dahlbomii and B. terrestris were collected between 12 and 22 November 2013 around the Huinay Scientific Field Station, in southern Chile. The station $\left(42^{\circ} 22^{\prime} \mathrm{S}, 72^{\circ} 24^{\prime} \mathrm{W}\right)$ is located in the Commune of Hualaihué, in the 10th Region of Chile, between the Comau fjord in the Province of Palena and the border with the Republic of Argentina (northern Patagonia). The study site is located in a temperate forest coastal area known to be particularly rich in endemic fauna and flora, and thus considered a priority conservation area $[31,32]$.

Insects were collected from 9:00 to 17:00 (solar time), by netting and while foraging on flowering plants. Individuals were killed by freezing, and after initial morphological analyses (see below), they were stored in $70 \%$ ethanol for further morphological investigations (see below).

Based on morphometric data provided in [33] and a comparison with size of workers collected in the summer of 2012 at the same locality [34], it was clear that only queens of B. dahlbomii were collected. A comparison of our size data with those provided in the literature [16,35-37] revealed that all except one collected individuals of $B$. terrestris were queens. The only exception was one individual which clearly had a size according to a worker status (body mass: $167 \mathrm{mg}$, wing total area: $91 \mathrm{~mm}^{2}$ ), and it was removed from the analysis. The period of collection seemed thus to coincide with the time of colony foundation and production of the first worker brood [16]. Occasional observations of $B$. dahlbomii queens performing a nest-searching patrolling behaviour on the soil (Fig. $1 \mathrm{C}$ and D) further suggested that the study period was within the colony founding period. A total of 34 queens of $B$. dahlbomii and 21 queens of $B$. terrestris were studied morphologically. Two further collected individuals proved to belong to another alien species, B. ruderatus (Fabricius), which was not included in the analysis due to the small sample size.

\subsection{Flight morphology}

Within 2-3 hours after collection, the bees were weighed with an electronic balance (Precisa Series 320 XB, model 120 A, Precisa Gravimetrics AG, Switzerland) to the nearest $0.0002 \mathrm{~g}$ (body mass, $M_{\mathrm{b}}$ ). We then separated the thorax from the rest of the body, including wings, weighed it (thorax mass, $M_{\mathrm{t}}$ ) and measured the thorax width $\left(W_{\mathrm{t}}\right)$. FMR was calculated as $\left(0.95 \times\left(M_{\mathrm{t}} / M_{\mathrm{b}}\right)\right)$ for each specimen [17]. For both species, we predicted the maximum food load mass that can be carried in flight after a successful take off $\left(\operatorname{Load}_{\max }\right)$ according to the regression equation of maximum lift force vs flight muscle mass for
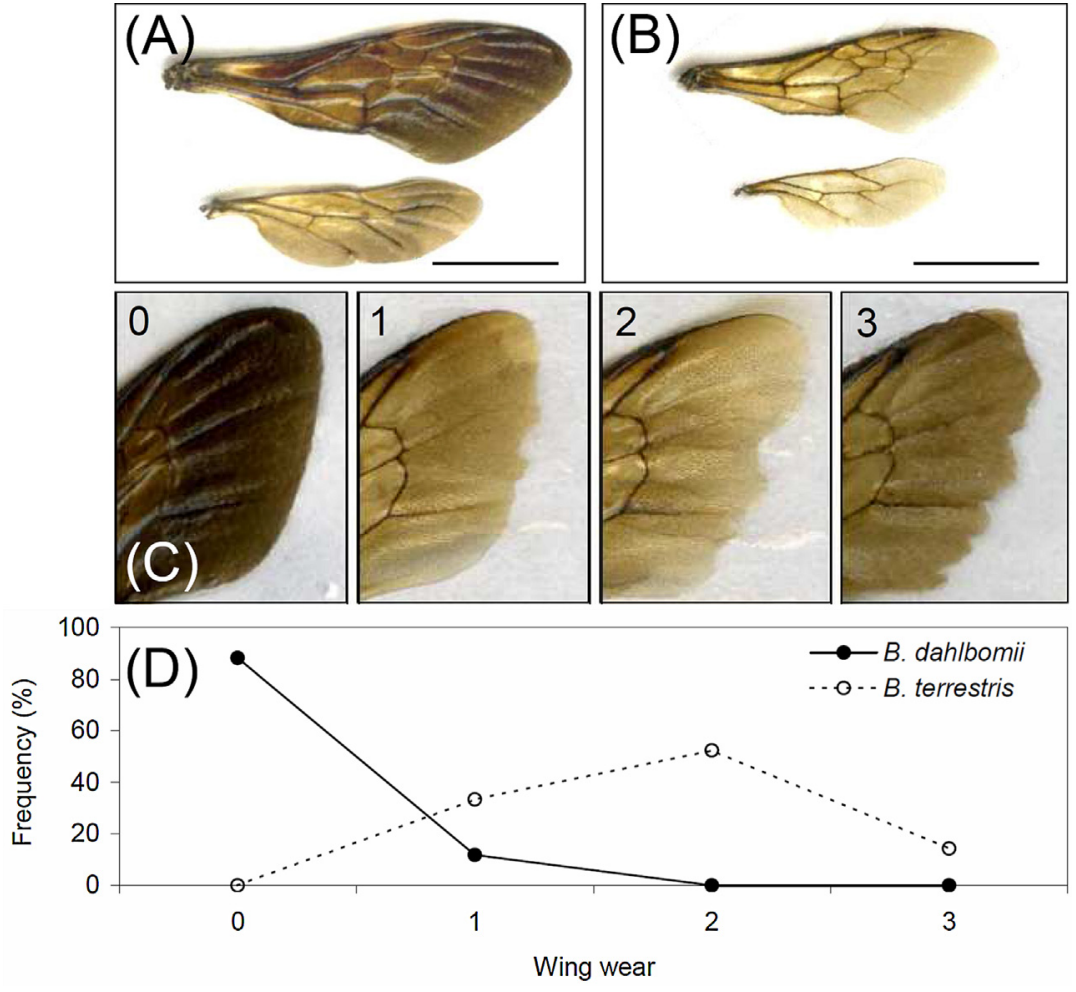

Fig. 2. (Colour online) Examples of one pair wings of (A) Bombus dahlbomii and (B) Bombus terrestris (bar $=0.7 \mathrm{~cm}$ ). (C) shows one example for each rank of wing wear (0: B. dahlbomii, 1-3: B. terrestris), and (D) shows the frequency distribution of wing wears among the queens of the two species. 
bees and wasps provided in Marden [17]: $\operatorname{Load}_{\max }=((10-$ base power of $\left.\left(\log \left(0.95 \times M_{\mathrm{t}}\right) \times 1.01+1.76\right)\right) /$ gravity acceleration) $\left.-M_{\mathrm{b}}\right)$ ).

At the Museo Nacional de Ciencias Naturales (CSIC, MNCN) (Madrid, Spain), we carried out further morphological investigations. One wing pair (fore wing and hind wing) of all individuals was scanned on an Epson 4990 flatbed scanner (1200 dpi) (Fig. 2A). The software ImageJ (National Institute of Mental Health, Bethesda Maryland, USA) was used for wing size and shape analysis. We calculated with this software individual wing lengths and wing areas. Measures on wings were taken to the nearest $0.002 \mathrm{~mm}$. The total wing area $\left(A_{\mathrm{w}}\right)$ refers to the area of both wing pairs and was obtained by doubling the previous measurements of the forewing and hindwing [38]. We then calculated the wing loading WL $\left(M_{\mathrm{b}} / A_{\mathrm{w}}\right)$ [22] for each individual. Assuming that the efficiency of the flight muscle does not vary per unit mass of muscle, the power of the flight motor will vary with the total mass of muscle [18]. Under this generally accepted assumption, the Excess Power Index (EPI) was calculated as $\sqrt{F M R^{2} / W L}[15]$.

The wing aspect ratio (AR) is a general dimensionless representation of wing shape, and it increases for narrower (elongated) wings. For the wing pair, AR was calculated from the forewing length $\left(L_{\mathrm{fw}}\right)$ and the total wing area $\left(A_{\mathrm{w}}\right)$ as $\left(4 \times L_{\mathrm{fw}}{ }^{2} / A_{\mathrm{w}}\right)$ [39]. Because bumblebee wings accumulate wear with age (in particular due to the increased frequency of wing collisions with vegetation) [40], and because wear reduces the wing area, thus affecting overall flight morphology [41], we also recorded forewing wear in a scale ranging from 0 (no signs of wear) to 3 (very worn) [42] (Fig. 2B).

\subsection{Statistical analysis}

Raw data for all continuous variables were normally distributed (Jarque-Bera test, JB $<3.87, P>0.05$ ), so that statistical analyses were performed on untransformed values. To test for differences in FMR, WL, EPI and AR between the queens of the two Bombus species, we performed analyses of covariance (ANCOVA, stepwise procedure) in which species, wing wear (as categorical variable), body mass and thorax width (as continuous variables) entered as explanatory factors. The Pearson correlation test was used to verify linear relationships between morphological parameters.

All the statistics were performed with the software XLSTAT 2011 (Addinsoft ${ }^{\mathbb{R}}$ ). In the text and tables, means are expressed $\pm \mathrm{SE}$, and medians are expressed together with the 1 st and 3rd quartiles.

\section{Results}

In the middle of November at the study site, all except four $B$. dahlbomii queens had completely unworn wings, with four having little damages (rank 1); on the other hand, all $B$. terrestris queens had at least wings with wear in rank 1 , with half falling in rank 2 (11 out of 21) (Fig. 2C, Table 1).

$B$. dahlbomii and B. terrestris significantly differed in body mass, the former being $40 \%$ heavier than the latter (Table 1). A similar difference was found in thorax mass (Table 1). Total wing area was $35 \%$ greater in B. dahlbomii, but the difference from $B$. terrestris in forewing length was only of $16 \%$ (Table 1, Fig. 2A). These figures resulted in B. terrestris having a $9 \%$ lower WL than B. dahlbomii and a very small AR difference between the two species ( $2 \%$ lower in B. terrestris), while FMR was virtually identical (Table 1). The two species were estimated to have values of Load $_{\text {max }}$ virtually identical to their respective body mass (Table 1), so that queens would be able to carry in flight, on the whole, twice their fresh body weight.

FMR variance among the studied females was explained only by body mass and wing wear (Table 2, Fig. 3A). In particular, larger $(t=-3.83)$ and more worn (wear-0: $t=1.37$ ) queens had lower FMR. WL was positively affected by body mass $(t=11.88)$ and the effect of the species was also significant (higher WL for B. dahlbomii) $(t=-5.76$ ) (Table 2, Fig. 3B). AR was positively explained by thorax width $(t=8.31)$ and not by species (Table 2, Fig. $3 C)$. WL and AR were not affected by wing wear. EPI was negatively affected by body mass $(t=-7.41)$ and it was $4 \%$ higher in $B$. terrestris $(t=4.38)$. Thus, after controlling for variation in body size (mass or length) and wing wear, B. dahlbomii and

Table 1

Descriptive statistics of all variables for Bombus dahlbomii and Bombus terrestris. Data are expressed as mean value \pm standard error [minimum-maximum], except for wing wear, which being categorical is expressed as minimum-maximum values.

\begin{tabular}{|c|c|c|}
\hline Variable & B. dahlbomii & B. terrestris \\
\hline Body mass (g) & $1.08 \pm 0.04[0.67-1.50]$ & $0.64 \pm 0.02[0.44-0.79]$ \\
\hline Thorax mass $(\mathrm{g})$ & $0.42 \pm 0.01[0.27-0.55]$ & $0.25 \pm 0.01[0.16-0.29]$ \\
\hline Thorax width (mm) & $9.09 \pm 0.14[8.21-10.02]$ & $7.53 \pm 0.09[6.85-8.57]$ \\
\hline Flight muscle ratio (FMR) & $0.37 \pm 0.00[0.31-0.41]$ & $0.37 \pm 0.01[0.32-0.42]$ \\
\hline Maximum theoretical load $\left(\operatorname{Load}_{\max }\right)(\mathrm{g})$ & $1.08 \pm 0.04[0.70-1.48]$ & $0.63 \pm 0.02[0.37-0.75]$ \\
\hline Area of fore wing $\left(\mathrm{cm}^{2}\right)$ & $1.00 \pm 0.02[0.74-1.27]$ & $0.65 \pm 0.01[0.48-0.72]$ \\
\hline Area of hind wing $\left(\mathrm{cm}^{2}\right)$ & $0.47 \pm 0.01[0.33-0.62]$ & $0.31 \pm 0.01[0.23-0.35]$ \\
\hline Total wing area $\left(\mathrm{cm}^{2}\right)$ & $2.92 \pm 0.06[2.25-3.57]$ & $1.91 \pm 0.04[1.42-2.10]$ \\
\hline Wing loading $\left(\mathrm{g} / \mathrm{cm}^{2}\right)(\mathrm{WL})$ & $0.37 \pm 0.01[0.28-0.47]$ & $0.34 \pm 0.01[0.30-0.39]$ \\
\hline Excess Power Index (EPI) & $0.61 \pm 0.01[0.49-0.71]$ & $0.64 \pm 0.01[0.51-0.76]$ \\
\hline Length of fore wing $(\mathrm{cm})$ & $2.08 \pm 0.02[1.84-2.32]$ & $1.67 \pm 0.02[1.49-1.94]$ \\
\hline Length of hind wing $(\mathrm{cm})$ & $1.41 \pm 0.03[1.14-2.03]$ & $1.14 \pm 0.02[0.94-1.47]$ \\
\hline Wing aspect ratio (AR) & $5.95 \pm 0.12[4.49-7.64]$ & $5.85 \pm 0.15[5.02-7.29]$ \\
\hline Wing wear & $0.00-1.00$ & $1.00-3.00$ \\
\hline
\end{tabular}


Table 2

ANCOVAs performed to test for differences in flight muscle ratio (FMR), wing loading (WL), wing aspect ratio (AR) and excess power index (EPI) between Bombus dahlbomii and Bombus terrestris. Only the explanatory variables which entered in the final model after the stepwise procedure are shown.

\begin{tabular}{|c|c|c|c|c|c|c|}
\hline Variable & Source & $D F$ & SS & $M S$ & $F$ & $P$ \\
\hline \multirow[t]{4}{*}{ FMR } & Model & 4 & 0.008 & 0.002 & 4.563 & 0.003 \\
\hline & Error & 50 & 0.023 & 0.000 & & \\
\hline & $\begin{array}{l}\text { Wing } \\
\text { wear }\end{array}$ & 3 & 0.004 & 0.001 & 3.258 & 0.029 \\
\hline & $\begin{array}{l}\text { Body } \\
\text { mass }\end{array}$ & 1 & 0.004 & 0.004 & 9.872 & 0.003 \\
\hline \multirow[t]{4}{*}{ WL } & Model & 2 & 0.085 & 0.043 & 83.326 & $<0.0001$ \\
\hline & Error & 52 & 0.027 & 0.001 & & \\
\hline & $\begin{array}{l}\text { Body } \\
\text { mass }\end{array}$ & 1 & 0.072 & 0.072 & 98.782 & $<0.0001$ \\
\hline & Species & 1 & 0.017 & 0.017 & 10.855 & 0.002 \\
\hline \multirow[t]{3}{*}{ AR } & Model & 2 & 15.291 & 7.646 & 34.571 & $<0.0001$ \\
\hline & Error & 52 & 11.500 & 0.221 & & \\
\hline & $\begin{array}{l}\text { Thorax } \\
\text { width }\end{array}$ & 1 & 15.499 & 15.499 & 70.082 & $<0.0001$ \\
\hline \multirow[t]{4}{*}{ EPI } & Model & 2 & 0.118 & 0.059 & 29.378 & $<0.0001$ \\
\hline & Error & 52 & 0.105 & 0.002 & & \\
\hline & $\begin{array}{l}\text { Body } \\
\text { mass }\end{array}$ & 1 & 0.088 & 0.088 & 43.813 & $<0.0001$ \\
\hline & Species & 1 & 0.039 & 0.039 & 4.214 & 0.045 \\
\hline
\end{tabular}

DF: degrees of freedom; SS: sum of squares; MS: mean squares.

B. terrestris significantly differed only in WL (higher in the former) and, more weakly, in EPI (higher in the latter).

A negative linear correlation was found between FMR and WL in $B$. terrestris $(r=-0.56, n=21, P=0.008)$, though not in B. dahlbomii ( $r=-0.31, n=34, P=0.07)$; on the other hand, FMR was not correlated with AR in both $B$. terrestris $(r=0.24, n=21, P=0.07)$ and in B. dahlbomii $(r=-0.06$, $n=34, P=0.72)$. WL and AR were positively correlated in both $B$. dahlbomii $(r=0.48, n=34, P=0.02)$ and $B$. terrestris $(r=0.74, n=21, P=0.006)$. In both species, EPI was negatively correlated with WL (B. dahlbomii: $r=-0.83$, $n=34, \quad P<0.0001 ; \quad B$. terrestris: $\quad r=-0.81, \quad n=21$, $P<0.0001)$ and positively correlated with FMR (B. dahlbomii: $r=0.78, n=34, P<0.0001 ; B$. terrestris: $r=0.93, n=21, P<0.0001)$.

\section{Discussion}

$B$. terrestris L. is a native of temperate Eurasia and expanded its range since the 1800 s. This species has been introduced as a pollinator in different countries, including New Zealand [43], Chile [3], Japan [44] and Australia (Tasmania only) [45]. In all these areas, this bumblebee species was observed to spread quickly, becoming a great competitor of native pollinators [44,46-49].

Previous studies recognize a number of possible factors which would account for the rapid spread of $B$. terrestris in the invasion areas. In particular, it would be favoured by high migration ability, high adaptability under adverse climatic conditions in various habitats, polylectic foraging strategies, foraging over wide distances, production of a higher number of gynes (in particular in commercial
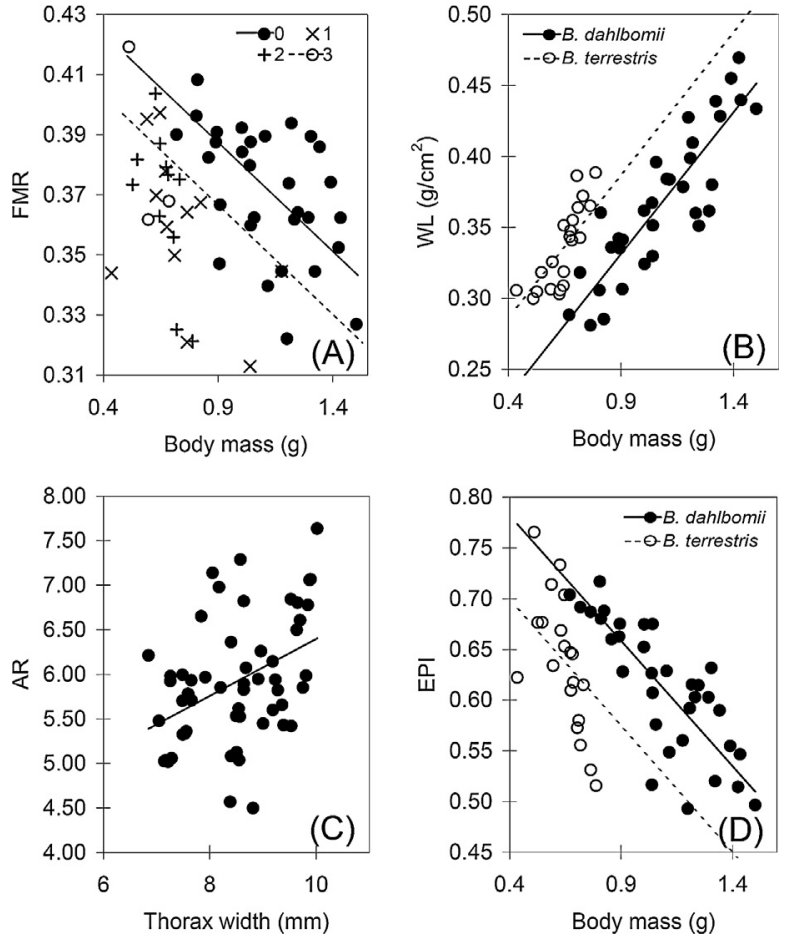

Fig. 3. Dispersion plots showing the relationships between (A) body mass and flight muscle ratio (FMR), (B) body mass and wing loading (WL), (C) thorax width and wing aspect ratio (AR), and (D) body mass and excess power index (EPI). Full (Bombus dahlbomii) or dashed (Bombus terrestris) black lines represent the adjustment to the significant linear models, except in (A), where the lines represent the adjustment to the significant linear models of wing wear.

apiaries), and transmission of pathogens to the local species $[44,48,50]$.

For the specific case of the invasion of Patagonia by B. terrestris, the potential roles of exploitative competition [14] and, supported by stronger evidence, of pathogen co-introduction $[5,15]$, were identified. The invasion success of $B$. terrestris may also be increased by the fact that queens of this species emerge earlier than native bumblebees during the season, as suggested by our wing wear data.

Here we evaluated the differences in morphological traits related with flight between $B$. dahlbomii and $B$. terrestris queens. The role of flight morphology could be hypothesized as important in the invasion process of $B$. terrestris. First, the foraging distance in this species can be as large as up to $4-5 \mathrm{~km}[49,51]$ and its spread velocity can be as high as $25 \mathrm{~km} /$ year (Tasmania: [45]) to $90 \mathrm{~km} /$ year (New Zealand: [52]) to $200 \mathrm{~km} /$ year (Patagonia: [5]). Second, a greater flight ability not only may increase foraging and spreading, but also the probability to escape predators [19].

The FMR values recorded in this study fall in the range observed for other bumblebee species (0.26-0.40) [38], and values are similar for both our studied species. However, we found a strong negative dependence of FMR by body mass in $B$. terrestris, with a (much weaker) trend for $B$. dahlbomii. Agreeing with this result, in a study 
in which the muscle mass in B. terrestris was empirically measured, Josephson \& Ellington [53] found that the allometric coefficient defined by the slope of the line relating $\log$ (muscle mass) and $\log$ (body mass) was less than 1 , indicating that small individuals have a proportionally larger muscle than large ones do. Thus, smaller bumblebee queens (particularly in $B$. terrestris) would be favoured by having a greater FMR. A greater FMR seemed to be associated with the ability to carry large loads among central-place foraging Hymenoptera [38,54], and within species, larger individuals are generally able to carry larger loads [54,55]; furthermore, FMR has been positively correlated with escape ability in butterflies [19]. Empirical studies showed that, while FMR increases, manoeuvrability and acceleration capacity in flight increase [17]. Variation in the relative size of flight muscles also affects the thermal breadth for flight (i.e. the range of ambient and muscle temperature over which flight is possible), so that insects with higher FMRs should be capable of maintaining flight at lower thoracic temperatures [18], an important trait in the cold spring of Patagonia (about $12-18{ }^{\circ} \mathrm{C}$ maximum daily temperature at our study site in November).

WL, after control for body mass, was significantly lower in $B$. terrestris, thus possibly improving its performance in flight. The values recorded for the two studied species (0.34-0.37) fall close to the upper limit recorded for other bumblebees (0.17-0.40), with larger species having greater WL $[38,56]$. The effect of body mass was strong, with larger queens within both species having greater WL. Such allometry in wing size-body size relationship is wellknown in Hymenoptera at both individual and species levels $[38,57,58]$. Empirical studies have shown that a reduced WL would allow a more energetically efficient flight and take off at higher speed $[21,22,29]$, and would be associated with an improved ability to fly at low temperatures [24]. A previous work on bumblebees [57] showed that a reduced flight metabolic rate is associated with lower wing loading at an intra-specific level, which could ultimately increase flight duration, assuming constant nectar loads. When looking at FMR and WL in one single parameter, the greater EPI in $B$. terrestris could be suggested to essentially provide a reduced flight cost per unit time, which equates to the possibility of enhanced flight duration $[25,26]$.

Previous studies on Bombus, and particularly on $B$. terrestris, reported AR values similar to those found by us (5.85-6.56 on average per study) [35,59]. Data also shows that larger bumblebee species tend to have higher AR [56,59], though this was not true in our case (B. terrestris had only $2 \%$ lower AR). Although AR increased with thorax width, it did not vary with body mass. However, individuals with greater WL also had greater AR. This would suggest that individuals not benefiting by having higher WL may have certain benefits by having higher AR. For example, bird species or individuals with greater AR are more efficient migrants, and their energetic demand per unit distance travelled is lower [60]. Furthermore, a flight parameter closely associated with acceleration capacity was positively correlated with AR in a butterfly [23].
In any case, taken together, the considerations above agree with the general suggestion of a progressively compromised flight performance at greater body masses in bees $[40,61,62]$.

It is interesting to note that, in Japan, the large native B. hypocrita Pérez (queen head width about $7 \mathrm{~mm}$ ) is also currently being heavily displaced by $B$. terrestris (queen head width about 4-6 $\mathrm{mm}$ ), while the smaller native species, Bombus pseudobaicalensis Vogt (queen head width about 4.5 ) is not showing a noticeable change in abundance ([44]; data of head widths from $[63,64]$ ). Thus, as it occurs in Patagonia, in Japan the larger native bumblebee may be more threatened by $B$. terrestris. Four other native species occur in Japan, with queens being either smaller than (head width about $3.5 \mathrm{~mm}$ ) or similar to (head with about $4.5 \mathrm{~mm}$ ) B. terrestris queens [63,64], but for these species, as far as we know, no data are available about their possible declines.

Experiments formally linking the studied morphological parameters with flight performance may help to explain the observed quick and wide spread of this alien species in Patagonia in the last few years. For example, in the laboratory, one could measure, at different temperature regimes, thorax temperature excess, flight metabolic rate, wing-beat frequency, and speed/acceleration ability in different-size queens of the two species. In the field, mark-recapture and radio-tracking methods could be used to evaluate the maximum foraging distance of both species. A further method to disclose the relationship between invasion success and morphology could be to compare the morphology of $B$. terrestris with those of different native Bombus species across invaded localities and years, correcting the results for the common ancestor.

\section{Disclosure of interest}

The authors declare that they have no conflicts of interest concerning this article.

\section{Acknowledgements}

We are indebted to the staff at the Huinay Biological Station for the kind support during the study. The study was funded by the program "Ayudas para la realización de estancias de investigación en el centro científico de la Fundación Huinay" (CSIC-Endesa) grants 2012 and 2013 to JLNA and CP; CP was also granted by a postdoctoral contract (Program JAE-Doc "Junta para la Ampliación de Estudios” funded by the Spanish Research Council (CSIC) and the ESF. We are indebted with John Jennings (University of Adelaide) for his kind review of the English. This is the publication No. 108 of the Huinay Scientific Field Station.

\section{References}

[1] A.H. Abrahamovich, N.B. Díaz, J.J. Morrone, Distributional patterns of the neotropical and andean species of the genus Bombus (Hymenoptera: Apidae), Acta. Zool. Mex. Nueva Ser. 20 (2004) 99-117.

[2] J. Montalva, L. Dudley, M.K. Arroyo, H. Retamales, H.A. Abramovich, Geographic distribution and associated flora of native and introduced bumble bees (Bombus spp.), J. Apicult. Res. 50 (2011) 11-21. 
[3] L. Ruz, Bee pollinators introduced to Chile: a review, in: P.G. Kevan, V.L. Imperatriz-Fonseca (Eds.), Pollinating bees 2002: the conservation link between agriculture and nature. Proceedings of workshop: conservation and sustainable use of pollinators in agricultute, with emphasis on bees, Brasilia Ministry of Environment, Sao Paulo, 2002.

[4] C.L. Morales, M.P. Arbetman, S.A. Cameron, M.A. Aizen, Rapid ecological replacement of a native bumble bee by invasive species, Front. Ecol. Environ. 11 (2013) 529-534.

[5] R. Schmid-Hempel, M. Eckhart, D. Goulson, D. Heinzmann, C.E. Lange, S. Plischuk, et al., The invasion of southern South America by imported bumblebees and associated parasites, J. Anim. Ecol. 83 (2014) 823-837.

[6] J.L. Lockwood, P. Cassey, T. Blackburn, The role of propagule pressure in explaining species invasions, Trends. Ecol. Evol. 20 (2005) 223-228.

[7] T.M. Blackburn, J.L. Lockwood, P. Cassey, Avian invasions. The ecology and evolution of exotic birds, Oxford University, Oxford, 2009.

[8] R.P. Duncan, T.M. Blackburn, P. Cassey, Factors affecting the release, establishment and spread of introduced birds in New Zealand, in: R.B. Allen, W.G. Lee (Eds.), Biological invasions in New Zealand, Springer, Dordrecht, 2006, pp. 137-154.

[9] D. Sol, S. Timmermans, L. Lefebvre, Behavioural fl exibility and invasion success in birds, Anim. Behav. 63 (2002) 495-502.

[10] T.P. McGlynn, Non-native ants are smaller than related native ants, Am. Nat. 154 (1999) 690-699.

[11] P.J. Lester, Determinants for the successful establishment of exotic ants in New Zealand, Divers. Distrib. 11 (2005) 279-288.

[12] E.B. Mondor, M.N. Tremblay, R.H. Messing, Morphological and ecological traits promoting aphid colonization of the Hawaiian Islands, Biol. Invasion. 9 (2007) 87-100.

[13] T.M. Blackburn, M.J. Monroe, B. Lawson, P. Cassey, J.G. Ewen, Body size changes in passerine birds introduced to New Zealand from the UK, NeoBiota 17 (2013) 1-18.

[14] J.A. Madjidian, C.L. Morales, H.G. Smith, Displacement of a native by an alien bumblebee: lower pollinator efficiency overcome by overwhelmingly higher visitation frequency, Oecologia 156 (2008) 835-845.

[15] M.P. Arbetman, I. Meeus, C.L. Morales, M.A. Aizen, G. Smagghe, Alien parasite hitchhikes to Patagonia on invasive bumblebee, Biol. Invasion. 15 (2013) 489-494.

[16] D. Goulson, Bumblebees: their behaviour ecology and conservation, Oxford University Press, Oxford, 2010.

[17] J.H. Marden, Maximum lift production during takeoff in flying animals, J. Exp. Biol. 130 (1987) 235-258.

[18] J.H. Marden, Variability in the size, composition, and function of insect flight muscle, Annu. Rev. Physiol. 62 (2000) 157-178.

[19] J.H. Marden, P. Chai, Aerial predation and butterfly design: how palatability, mimicry and the need for evasive flight constrain mass allocation, Am. Nat. 138 (1991) 15-36.

[20] U.M. Norberg, Wing design, flight performance, and habitat use in bats, in: P.C. Wainwright, S.M. Reilly (Eds.), Ecological morphology: integrative organismal biology, University of Chicago Press, Chicago, 1994 pp. 205-239.

[21] M.J. Angelo, F. Slansky Jr., Body building by insects: trade-offs in resource allocation with particular reference to migratory species, Fla. Entomol. 67 (1984) 22-41.

[22] C.P. Ellington, Limitations on animal flight performance, J. Exp. Biol. 160 (1991) 71-91.

[23] K. Berwaerts, H. Van Dyck, P. Aerts, Does flight morphology relate to flight performance? An experimental test with the butterfly Pararge aegeria, Funct. Ecol. 16 (2002) 484-491.

[24] M.R. Frazier, J.F. Harrison, S.D. Kirkton, S.P. Roberts, Cold rearing improves cold-flight performance in Drosophila via changes in wing morphology, J. Exp. Biol. 211 (2008) 2116-2122.

[25] H.R. Hepburn, S.E. Radloff, G.R. Steele, R.E. Brown, Dimensional aspects of flight in the honeybees of Africa, J. Apic. Res. 37 (1998) 147-154.

[26] H.R. Hepburn, S.E. Radloff, S. Fuchs, Flight machinery dimensions of honeybees, Apis mellifera, J. Comp. Physiol. [B] 169 (1999) 107-112.

[27] S.E. Radloff, H.R. Hepburn, G. Koeniger, Comparison of flight design of Asian honeybee drones, Apidologie 34 (2003) 353-358.

[28] Seidelmann, Karsten, Optimal progeny body size in a solitary bee, Osmia bicornis (Apoidea: Megachilidae), Ecol. Entomol. (2014), http://dx.doi.org/10.1111/een.12145.

[29] A. Ahmed, A comparative study on flight surface and aerodynamic parameters of insects, birds and bats, Indian. J. Exp. Biol. 225 (1984) 270-278.

[30] C.P. Ellington, The aerodynamics of hovering insect flight, Philos. Trans. R. Soc. B 305 (1984) 1-181.

[31] V.H. Heywood, Global biodiversity assessment, Cambridge University Press, Cambridge, 1995.

[32] T.R. New, M.J. Samways, Insect conservation in the southern temperate zones: an overview, Aust. Entomol. 53 (2014) 26-31.
[33] M.M. Murúa, A.A. Grez, J.A. Simonetti, Changes in wing length in the pollinator Bombus dahlbomii occurring with the fragmentation of the Maulino forest, Chile, Cienc. Investig. Agrar. 38 (2011) 391-396.

[34] C. Polidori, J.L. Nieves-Aldrey, F. Gilbert, G. Rotheray, Hidden in taxonomy: Batesian mimicry by a syrphid fly towards a Patagonian bumblebee, Insect. Conserv. Divers. 7 (2014) 32-40.

[35] A. Hedenström, C.P. Ellington, T.J. Wolf, Wing wear, aerodynamics and flight energetics in bumblebees (Bombus terrestris): an experimental study, Funct. Ecol. 15 (2001) 417-422.

[36] J. Spaethe, A. Weidenmuller, Size variation and foraging rate in bumblebees (Bombus terrestris), Insectes. Soc. 49 (2002) 142-146.

[37] M.R. Amin, Y.J. Kwan, Photoperiod and relationship with body mass and size in bumblebee, Bombus terrestris L. (Hymenoptera: Apidae) workers, Bangladesh. J. Sci. Ind. Res. 46 (2011) 447-450.

[38] C. Polidori, A. Crottini, L. Della Venezia, J. Selfa, N. Saino, D. Rubolini, Food load manipulation ability shapes flight morphology in females of central-place foraging Hymenoptera, Front. Zool. 10 (2013) 36.

[39] R. Buchwald, R. Dudley, Limits to vertical force and power production in bumblebees (Hymenoptera: Bombus impatiens), J. Exp. Biol. 213 (2010) 426-432.

[40] D.J. Foster, R.V. Cartar, What causes wing wear in foraging bumble bees? J. Exp. Biol. 214 (2011) 1896-1901.

[41] S.A. Johnson, V.R. Cartar, Wing wear, but not asymmetry in wear, affects load-lifting capability in bumble bees Bombus impatiens, Can. J. Zool. 92 (2014) 179-184.

[42] C. Polidori, M. Federici, C. Papadia, F. Andrietti, Nest sharing and provisioning activity of females of the digger wasp, Cerceris rubida (Hymenoptera: Crabronidae), Ital. J. Zool. 73 (2006) 55-65.

[43] D. Goulson, M.E. Hanley, Distribution and forage use of exotic bumblebees in South Island, New Zealand, N. Z. J. Ecol. 28 (2004) 225-232.

[44] M.N. Inoue, J. Yokoyama, I. Washitani, Displacement of Japanese native bumblebees by the recently introduced Bombus terrestris (L.) (Hymenoptera: Apidae), J. Insect. Conserv. 12 (2008) 135-146.

[45] A.B. Hingston, J. Marsden-Smedley, D.A. Driscoll, S. Corbett, J. Fenton, R. Anderson, et al., Extent of invasion of Tasmanian native vegetation by the exotic bumblebee Bombus terrestris (Apoidea: Apidae), Aust. Ecol. 27 (2002) 162-172

[46] A. Dafni, P. Kevan, C.L. Gross, K. Goka, Bombus terrestris, pollinator, invasive and pest: an assessment of problems associated with its widespread introductions for commercial purposes, Appl. Entomol. Zool. 45 (2010) 101-113.

[47] K. Hergstrom, R. Buttermore, A. Hopkins, V. Brown, The distribution and spread of the bumblebee Bombus terrestris (L.) in Tasmania since introduction in 1991, with notes on food plants, Kanunnah 1 (2005) $103-125$.

[48] C. Matsumura, J. Yokoyama, I. Washitani, Invasion status and potential ecological impacts of an invasive alien bumblebee, Bombus terrestris L. (Hymenoptera: Apidae) naturalized in Southern Hokaido, Japan, Global. Environ. Res. 8 (2004) 51-66.

[49] A.B. Hingston, Is the exotic bumblebee Bombus terrestris really invading Tasmanian natural vegetation? J. Insect. Conserv. 10 (2006) 289-293.

[50] N. Inari, T. Nagamitsu, T. Kenta, K. Goka, T. Hiura, Spatial and temporal pattern of introduced Bombus terrestris abundance in Hokkaido, Japan, and its potential impact on native bumblebees, Popul. Ecol. 44 (2005) 77-82.

[51] D. Goulson, J.C. Stout, Homing ability of bumblebees: evidence for a large foraging range? Apidologie 32 (2001) 105-112.

[52] J. Hopkins, History of the bumble bees in New Zealand: its introduction and results, N. Z. Dep. Apicult. Pub. 46 (1914) 1-29.

[53] R.K. Josephson, C.P. Ellington, Power output from a flight muscle of the bumblebee Bombus terrestris. I. Some features of the dorso-ventral flight muscle, J. Exp. Biol. 200 (1997) 1215-1226.

[54] J.R. Coelho, Effects of prey size and load carriage on the evolution of foraging strategies in wasps, in: C. Polidori (Ed.), Predation in the Hymenoptera: an evolutionary perspective, Transworld Research Network publishing, Kerala, 2011, pp. 23-38.

[55] C. Polidori, M. Gobbi, L. Chatenaud, D. Santoro, O. Montani, F. Andrietti, Taxon-biased diet preference in the "generalist" beetle-hunting wasp Cerceris rubida provides insights on the evolution of prey specialization in apoid wasps, Biol. J. Linnean. Soc. 99 (2010) 544-558.

[56] D.P. Abrol, Morphometrics and wing-stroke frequency of bumblebees, J. Indian. Inst. Sci. 71 (1991) 365-372.

[57] D.A. Skandalis, C.-A. Darveau, Morphological and physiological idiosyncrasies lead to interindividual variation in flight metabolic rate in worker bumblebees (Bombus impatiens), Physiol. Biochem. Zool. 85 (2012) 657-670

[58] C.-A. Darveau, P.W. Hochachka, D.W. Roubik, K. Welch, R.K. Suarez, Allometric scaling of flight energetics in panamanian orchid bees: 
a comparative phylogenetic approach, J. Exp. Biol. 208 (2005) 35813591.

[59] R. Dudley, C.P. Ellington, Mechanics of forward flight in bumblebees. I. Kinematics and morphology, J. Exp. Biol. 148 (1990) 19-52.

[60] W. Yong, F.R. Moore, Flight morphology, energetic condition, and the stopover biology of migrating thrushes, Auk 111 (1994)683-692.

[61] M.E. Dillon, R. Dudley, Allometry of maximum vertical force production during hovering flight of neotropical orchid bees (Apidae: Euglossini), J. Exp. Biol. 27 (2004) 417-425.
[62] S.P. Roberts, J.F. Harrison, R. Dudley, Allometry of kinematics and energetics in carpenter bees (Xylocopa varipunctata) hovering in variable-density gases, J. Exp. Biol. 207 (2004) 993-1004.

[63] M.N. Inoue, Size-dependent selection against small queens of the invasive bumblebee Bombus terrestris in Japan, Entomol. Exp. Appl. 138 (2011) 65-70

[64] R. Cueva del Castillo, D.J. Fairbairn, Macroevolutionary patterns of bumblebee body size: detecting the interplay between natural and sexual selection, Ecol. Evol. 2 (2012) 46-57. 